Buana Sains Vol 20 No 1: 41 - 48, 2020

\title{
KAJIAN POTENSI AGROWISATA DI KAWASAN WISATA COBAN JAHE, DESA PANDANSARI LOR, KECAMATAN JABUNG, KABUPATEN MALANG
}

\author{
Rizki Alfian, Debora Budiyono, dan Suryadi Umbu Ewang
}

Fakultas Pertanian, Universitas Tribhuwana Tunggadewi, Indonesia

\begin{abstract}
Pandansari Lor Village is one of the tourist villages in the District of Jabung, Malang. Pandansari Lor has the potential for agro-tourism so that tourist visits have increased every year. With the level of agro-tourism activities increasing the volume of visitors is increasing. In addition, the level of understanding of the local community towards agro-tourism is low so it needs to be socialized about agro-tourism. The purpose of this study is to examine the potential of agrotourism in Pandansari Lor village. The research was conducted in November to December 2019, using the inventory method or field survey, and SWOT analysis. Data collection is carried out by means of field observations, calculations, interviews and literature studies. Based on the results of the feasibility assessment of the agro-tourism area, Tegir Hamlet is a hamlet that has the potential to be developed into an agrotourism area because it is ranked first with a total weight of 3.85. Begawan and shadow hamlets have the same number of weights, which is 3.75 , which has the potential to be developed as an agro-tourism area while Kedawung Hamlet is the least potential because it is ranked the lowest at 2.85. The main alternative strategies are, optimizing existing agrotourism activities and other supporting agro-tourism objects and attractions, providing training and socialization related to agro-tourism and agriculture through collaboration with many related parties to expand the network on agro-tourism.
\end{abstract}

Keywords: Agro-tourism, Pandansari Lor; potential; tourism; village.

\section{Pendahuluan}

Agrowisata atau wisata pertanian merupakan alternativ aktivitas perjalanan wisata yang memanfaatkan lokasi atau sektor pertanian mulai dari awal produksi hingga diperoleh produk pertanian dalam berbagai sistem dan skala dengan tujuan memperluas pengetahuan, pemahaman, pengalaman, dan rekreasi di bidang pertanian (Nurisjah 2001). Pengembangan kawasan agrowisata menuntut pengelolaan ruang (tata ruang) yang lebih menyeluruh baik yang meliputi pengaturan, evaluasi, penertiban maupun peninjauan kembali pemanfaatan ruang sebagai kawasan agrowisata, baik dari sisi ekologi, ekonomi maupun sosial budaya (Balitbang 2011). Selain itu, berkembangnya agrowisata di sebuah desa dapat menghasilkan sistem pertanian yang bertahan dalam kurun waktu yang cukup lama dengan pola 
pengolahan yang berorientasikan pada kelestarian lingkungan.

Sumber daya yang dapat dimanfaatkan dalam kegiatan agrowisata dapat berupa sumber daya alami seperti komoditas pertanian, pemandangan alam, dan sumber daya lainnya seperti aktivitas dan budaya masyarakat. Pengembangan agrowisata memerlukan identifikasi potensi-potensi lanskap untuk mendukung agrowisata yang sesuai dengan potensi sumber daya alam dan kondisi sosial budaya masyarakatnya agar tercapainya kemantapan pengembangan objek agrowisata.
Penelitian ini bertujuan untuk: 1) mengkaji potensi Agrowisata di kawasan wisata Coban Jahe, 2) Memberikan rekomendasi untuk pengembangan agrowisata di kawasan wisata Coban Jahe, Desa Pandansari Lor, Kecamatan Jabung

\section{Metode Penelitian}

Penelitian ini dilakukan di Coban Jahe, Desa Pandansari Lor, Kecamatan Jabug, Kabupaten Malang. Penelitian ini dilakukan mulai dari bulan November hingga Desember 2019.

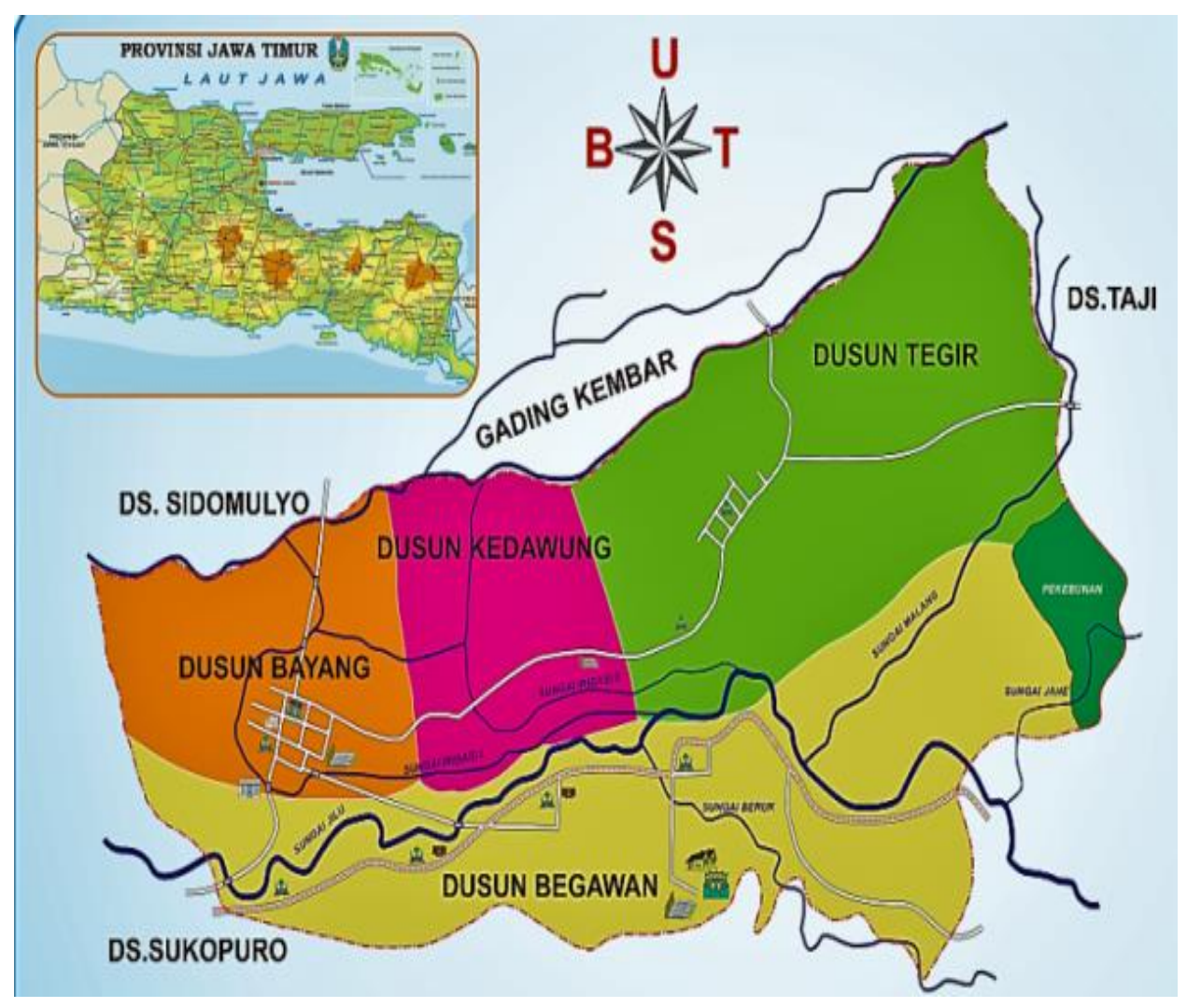

Gambar 1. Lokasi Penelitian 
Penelitian ini dengan menggunakan metode inventarisasi atau survei lapangan. Pengumpulan data dilakukan dengan cara pengamatan di lapangan, pengukuran, perhitungan, wawancara, dan studi literature. Data yang dikumpulkan meliputi aspek fisik, ekologi, sosial masyarakat, dan ekonomi. Wawacara dilakukan kepada pemerintah desa, masyarakat desa Pandansari lor.

Penelitian ini menggunakan metode deskriptif kualitatif, penelitian ini akan dilakukan beberapa tahapan yang mencakup tahapan persiapan, pengumpulan data, dan analisis kesesuaian dan kelayakan agrowisata, tahap penilaian, dan hasil akhir serta pelaporan.

Aspek yang akan dianalisis pada analisis kesesuaian dan kelayakan agrowisata adalah kondisi objek dan atribut pendukung kegiatan agrowisata Desa Pandansari Lor. Aspek-aspek tersebut dinilai berdasarkan kriteria kelayakan agrowisata menurut Smith (1989) dalam Maharani (2009) yang disesuaikan dan dimodifikasi dengan tujuan penelitian ini, seperti objek wisata pertanian, objek wisata alami, hingga fasilitas pendukung kegiatan agrowisata. Kriteria tersebut ditunjukkan pada tabel 1.

\section{Hasil dan Pembahasan Kondisi Umum}

Berdasarkan hasil inventarisasi di tapak maupun studi potensi didapatkan informasi terkait kondisi umum Coban Jahe, Desa Pandansari Lor. Karakter lanskap yang ditinjau dari aspek fisik, biofisik, sosial dan budaya, serta aspek agrowisata di Coban Jahe, Desa Pandansari Lor. Kawasan Coban Jahe terletak di Dusun Bengawan, Desa Pandansari Lor, Kecamatan Jabung, Kabupaten Malang dan masih berada di kawasan Perhutani RPH Sukopuro
Jabung dengan titik koordinat $7^{\circ} 58^{\prime}$ 19.91" S $113^{\circ} 6^{\prime} 54.84^{\prime \prime}$ E. Area Coban Jehe terdiri atas hutan alami dan sumber mata air yang mendukung beberapa keanekaragaman ekosistem untuk hidup di area tersebut. Secara geografis Coban Jahe terletak di daerah sumber air dengan topografi yang beragam. Luas Wilayah Desa Pandansari Lor adalah 470,485 Ha. Luas lahan yang ada terbagi ke dalam beberapa peruntukan, yang dapat dikelompokkan seperti untuk fasilitas umum,pemukiman,pertanian, perkebunan, kegiatan ekonomi dan lainlain.

\section{Aspek Biofisik}

Aspek biofisik yang dibahas dalam penelitian ini adalah vegetasi dan satwa. Vegetasi di Coban Jahe, Desa Pandansari Lor didominasi oleh jenis tanaman ketela, singkong dan sayuran yang berpotensi menjadi komoditas utama pada kegiatan agrowisata, sedangkan satwa yang berpotensi untuk agrowisata adalah hewan ternak salah satunya sapi perah.

\section{Aspek Sosial dan Budaya}

Karakter sosial budaya masyarakat diketahui melalui data dermografi desa yang ditunjang dengan persepsi dan preferensi pengunjung serta masyarakat Desa Pandansari Lor, kelembagaan yang berkembang di tingkat desa dan masyarakat, serta penilaian keberlanjutan masyarakat.

\section{Kependudukan}

Penduduk Desa Pandansari Lor Berdasarkan data Administrasi Pemerintahan Desa tahun 2010, jumlah penduduk Desa Pandansari Lor adalah 4.575 jiwa, dengan rincian 2.328 jiwa lakilaki dan 2.247 jiwa perempuan. Jumlah penduduk demikian ini tergabung dalam $1.420 \mathrm{KK}$. 


\section{Analisis Aspek Kesesuaian Dan Kelayakan Agrowisata}

Aspek yang akan dianalisis pada analisis kesesuaian dan kelayakan agrowisata adalah kondisi objek dan atribut pendukung kegiatan agrowisata Desa Pandansari Lor. Aspek-aspek tersebut dinilai berdasarkan kriteria kelayakan agrowisata menurut Smith (1989) dalam Maharani (2009) yang disesuaikan dan dimodifikasi dengan tujuan penelitian ini, seperti objek wisata pertanian, objek wisata alami, hingga fasilitas pendukung kegiatan agrowisata.

\section{Kelayakan Kawasan Agrowisata}

Objek dan atraksi agrowisata yang ada di Desa pandansari lor letaknya cukup tersebar di keempat dusun dan kegiatan agrowisata yang dapat dilakukan pun cukup beragam. Oleh karena itu, dibutuhkan penilaian terhadap kelayakan potensi agrowisata di dusun-dusun tersebut serta untuk mengetahui prioritas dalam pengembangan kawasan agrowisata. Untuk mengetahui hal tersebut dilakukan penilaian dengan rumus kelayakan kawasan agrowisata menurut Smith (1988) yang dikutip dalam Maharani (2009) seperti pada Tabel 1.

Berdasarkan penilaian kelayakan kawasan agrowisata pada tabel 2, Dusun Tegir menjadi dusun yang sangat berpotensi untuk dikembangkan menjadi kawasan agrowisata karena berada di peringkat pertama dengan jumlah bobot yaitu sebesar 3.85. Dusun begawan dan bayang memiliki jumlah bobot yang sama yaitu 3.75 menjadi dusun yang sangat berpotensi untuk dikembangkan sebagai kawasan agrowisata sedangkan Dusun Kedawung merupakan dusun yang kurang berpotensi karena berada pada peringkat terendah yaitu 2,85. Dari ke empat dusun Bentuk spasial dari kelayakan agrowisata ini dibentuk pula berdasarkan RT RW Desa Pandansari Lor, Kecamatan Jabung, Kabupaten Malang tahun 2007-2027.

Dari hasil penilaian kelayakan tersebut terdapat 3 dusun yaitu Dusun Tegir, Dusun Begawan dan Dusun Bayang yang sangat berpotensi dikarenakan pada eksisting erdapat Sumberdaya pertanian dan wisata yang cukup seperti lahan perkebunan ketela, perikanan, peternakan, wisata air terjun dan sarana prasaran lainnya. Sedangkan Dusun Kedawung yang memilik nilai kelayakan rendah merupakan lahan perbukitan dengan kemiringan yang curam.

Secara kelembagaan belum terdapat pengelolaan kawasan agrowisata yang terstruktur, namun preferensi warga dan aparatur desa sangat setuju terhadap pengembangan wisata Agrowisata pada Desa Pandansari Lor. Maka perlu dilakukan Peningkatan kapasitas SDM perdesaan untuk meningkatkan peran serta masyarakat dalam pengembangan desa wisata berbasis masyarakat. Faktorfaktor yang menentukan pengembangan agrowisata seperti; sistem usahatani terpadu, ciri pola kelembagaan lokal, dan program yang telah ada akan menghasilkan rumusan model pengembangan agrowisata berbasis masyarakat yang berorientasi pada nilai tambah dan keberlanjutan sistem pertanian (Budiarti dkk, 2013). 
R. Alfian, D. Budiyono, dan S.U. Ewang / Buana Sains Vol 18 No 1 : 41-48

Tabel 1. Kriteria kelayakan agrowisata

\section{No.}

Nilai

Obyek dan Atraksi Berbasis Pertanian (Bobot 15\%): Ketersediaan ragam dan keindahan areal pertanian seperti sawah, perkebunan, kolam, atau keramba

- Beragam obyek dan aktivitas pertanian disertai keindahan pemandangan pertanian

- Cukup beragam obyek dan aktivitas pertanian disertai keindahan pemandangan sekitarnya

- Cukup beragam obyek dan aktivitas pertanian disertai keindahan pemandangan sekitarnya

- Kurang beragam dan tak indah

2 Obyek dan Atraksi Alami (Bobot 10\%): Keindahan pemandangan alami (ekosistem, topografi, tanaman langka, satwa liar, air terjun) dan iklim (tropikal, udara yang bersih, suhu yang nyaman, dll)

- Beragam obyek alami dengan keindahan dan kenyamanan alami

- Cukup beragam obyek alami dengan keindahan dan kenyamanan alami

- Beragam obyek alami dengan keindahan dan kenyaman buatan

- Kurang obyek alami dengan keindahan dan kenyaman buatan

3 Obyek dan Atraksi Budaya/Sosial (Bobot 10\%): Perdesaan, perkotaan, bentukan arsitektur vernakular, festival budaya, dan atraksi budaya lokal

- Bernilai lokal tinggi, berjumlah relatif banyak, dilestarikan

- Bernilai lokal tinggi, berjumlah relatif banyak, kurang diperhatikan

- Bernilai lokal tinggi, berjumlah sedikit, kurang diperhatikan

- Tidak memiliki aset budaya lokal

4 Obyek dan Atraksi Sejarah (Bobot 5\%): Peninggalam kuno (kerahaan, situssitus dan bangunan sejarah/arkeologis), upacara keagamaan (temporal), lokasi historikal yang penting (kolonial, battle fields)

- Bersejarah, dijaga kelestariaannya

- Bersejarah, kurang diperhatikan

- Bersejarah, tidak dilestarikan

- Tidak bernilai sejarah

5 Akses (Bobot 10\%): Kemudahan untuk pencapaian lokasi, ketersediaanjalan.

- Jalan primer dekat, mudah dicapai, kondisi baik, kendaraan umum beragam, kondisi baik

- Jalan sekunder, kondisi sedang, kendaraan umum terbatas

- Jalan tersier, kondisi sedang, tidak ada kendaraan umum

- Tidak ada akses, tidak ada kendaraan umum 
R. Alfian, D. Budiyono, dan S.U. Ewang / Buana Sains Vol 18 No 1 : 41-48

\begin{tabular}{|c|c|c|}
\hline 6 & $\begin{array}{l}\text { Sumber daya Rekreasi dan Tempat Perbelanjaan (Bobot 10\%): Tempat Olah } \\
\text { raga, piknik, belanja, taman, museum, galer seni/budaya } \\
\text { - Tersedia, lengkap, kualitas baik dan terawat } \\
\text { - Ada beberapa, cukup terawat } \\
\text { - Ada beberapa, kurang terawat } \\
\text { - Tidak tersedia }\end{array}$ & $\begin{array}{c}4 \\
3 \\
2 \\
1\end{array}$ \\
\hline 7 & $\begin{array}{l}\text { Letak Dari Jalan Utama }(10 \%): \text { Kedekatan dengan jalur jalan utama wilayah } \\
\text { - Dekat }(<1 \mathrm{~km}) \\
\text { - Sedang }(1-3 \mathrm{~km}) \\
\text { - Cukup jauh }(3-5 \mathrm{~km}) \\
\text { - Sangat jauh }(>5 \mathrm{~km})\end{array}$ & $\begin{array}{l}4 \\
3 \\
2 \\
1\end{array}$ \\
\hline 8 & $\begin{array}{l}\text { Sarana Wisata (Bobot 10\%): Utilitas. Saran kesehatan, air bersih, fasilitas dan } \\
\text { penginapan } \\
\text { - Tersedia, lengkap, kualitas baik dan terawa } \\
\text { - Ada beberapa, cukup terawat } \\
\text { - Ada beberapa, kurang terawat } \\
\text { - Tidak tersedia }\end{array}$ & $\begin{array}{l}4 \\
3 \\
2 \\
1\end{array}$ \\
\hline 9 & $\begin{array}{l}\text { Pengelolaan agrowisata (Bobot 10\%): Pengelolaan dan Kelembagaan } \\
\text { Agrowisata } \\
\text { - Masyarakat mengelola dan ada lembaga masyarakat } \\
\text { - Masyarakat mengelola, tidak ada lembaga masyarakat } \\
\text { - Dikelola investor, ada kelembagaan masyarakat } \\
\text { - Dikelola investor dan tidak ada lembaga masyarakat }\end{array}$ & $\begin{array}{l}4 \\
3 \\
2 \\
1\end{array}$ \\
\hline 10 & $\begin{array}{l}\text { Program dan dan Aktivitas Agrowisata (Bobot } 10 \%) \\
\text { - Ada paket kunjungan, pelatihan, dan membuka kesempatan magang } \\
\text { - Ada paket kunjungan, pelatihan, tidak ada kesempatan magang } \\
\text { - Ada paket kunjungan, tetapi tidak ada pelatihan dan kesempatan magang } \\
\text { - Tidak ada paket kunjungan, pelatihan dan kesempatan magang }\end{array}$ & $\begin{array}{l}4 \\
3 \\
2 \\
1\end{array}$ \\
\hline
\end{tabular}

Sumber: Smith (1989) dalam Maharani (2009)

Tabel 2. Kelayakan kawasan agrowisata di Desa pandansari lor

\begin{tabular}{|c|c|c|c|c|c|c|c|c|c|c|c|}
\hline \multicolumn{11}{|c|}{ Kelayakan Agrowisata di Desa pandansari lor } & Jumlah \\
\hline Bobot & $15 \%$ & $10 \%$ & $10 \%$ & $5 \%$ & $10 \%$ & $10 \%$ & $10 \%$ & $10 \%$ & $10 \%$ & $10 \%$ & Terbobot \\
\hline Skoring & 1 & 2 & 3 & 4 & 5 & 6 & 7 & 8 & 9 & 10 & $\sum K K A$ \\
\hline Tegir & 4 & 4 & 4 & 2 & 4 & 4 & 4 & 4 & 4 & 3 & 3.85 \\
\hline Begawan & 4 & 3 & 4 & 3 & 4 & 4 & 4 & 3 & 4 & 3 & 3.75 \\
\hline Bayang & 4 & 4 & 3 & 4 & 4 & 3 & 4 & 4 & 4 & 2 & 3.75 \\
\hline Kedawung & 3 & 3 & 3 & 1 & 4 & 2 & 4 & 2 & 4 & 1 & 2.85 \\
\hline
\end{tabular}

Pembuatan rentang kelas klasifikasi:

$\mathrm{R}=\frac{3.85-2.85}{3}=0.33$; Sehingga klasifikasi yang diperoleh:

$\begin{array}{ll}\text { Sangat Berpotensi } & : 3.53-3.86 \\ \text { Berpotensi } & : 3.19-3.52 \\ \text { Kurang Berpotensi } & : 2.85-3.18\end{array}$


Alternatif strategi utama pada Desa Pandansari Lor yaitu; Mengoptimalkan kegiatan agrowisata dan objek wisata yang sudah ada, Memberikan pelatihan dan pendampingan kepada masayarakat lokal terkait agrowisata dan pertanian melalui kerja sama dengan banyak pihak terkait untuk memperluas jaringan mengenai agrowisata.

\section{Rekomendasi}

Berdasarkan hasil analisis yang telah dilakukan dengan menggunakan sejumlah metode pada aspek agrowisata dan pembentuk karakter lanskap di Coban Jahe Desa Pandansari Lor, diperoleh rekomendasi yang bisa digunakan untuk mengembangkan potensi agrowisata antara lain:

1. Membangun konektivitas antar dusun dan kawasan wisata Coban Jahe menjadi satuan produk wisata yang terintegrasi

2. Menerapkan sistem pengelolaan wisata berbasis masyarakat.

3. Membangun jejaring mitra bisnis pertanian baik secara lokal, regional hingga nasional

4. Melakukan tindak konservasi lingkungan guna memelihara lanskap pedesaan yang alami.

5. Melakukan kegiatan promosi baik melalui media cetak, atau online.

6. Menawarkan berbagai jasa wisata baik yang bersifat rekreatif, edukatif, dan exploratif.

7. Melengkapi sarana prasarana guna mendukung kenyamanan pengunjung.

8. Perlu dibentuk kelompok masyarakat sadar wisata pada setiap dusun yang terorganisir dengan baik

\section{Kesimpulan}

Desa pandansari lor memiliki potensi agrowisata yang terbentuk dari aspek fisik, biofisik, sosial dan budaya hingga memunculkan banyak objek dan atraksi agrowisata serta pendukungnya yang dapat dikembangkan. Berdasarkan penilaian kelayakan kawasan agrowisata, Dusun Tegir menjadi dusun yang sangat berpotensi untuk dikembangkan menjadi kawasan agrowisata karena berada di peringkat pertama dengan jumlah bobot yaitu sebesar 3.85. Dusun begawan dan bayang memiliki jumlah bobot yang sama yaitu 3.75 menjadi dusun yang sangat berpotensi untuk dikembangkan sebagai kawasan agrowisata sedangkan Dusun Kedawung merupakan dusun yang kurang berpotensi karena berada pada peringkat terendah yaitu 2,85. Berdasarkan hasil analisis kesesuaian lahan secara umum Desa Pandansari sesuai untuk dikembangkan sebagai kawasan agrowisata dengan beberapa rekomendasi : 1) Membangun konektivitas antar dusun dan kawasan wisata Coban Jahe menjadi satuan produk wisata yang terintegrasi, 2) Menerapkan sistem pengelolaan wisata berbasis masyarakat, 3) Membangun jejaring mitra bisnis pertanian baik secara lokal, regional hingga nasional, 4) Melakukan tindak konservasi lingkungan guna memelihara lanskap pedesaan yang alami, 5) Melakukan kegiatan promosi baik melalui media cetak, atau online, 6) Menawarkan berbagai jasa wisata baik yang bersifat rekreatif, edukatif, dan exploratif, 7) Melengkapi sarana prasarana guna mendukung kenyamanan pengunjung, 8) Perlu dibentuk kelompok masyarakat sadar wisata pada setiap dusun yang terorganisir dengan baik

\section{Daftar Pustaka}

David F R. 2008. Manajemen Strategi ke 10. Terjemahan oleh Budi S. Strategic Mangement: Concepts and Cases. Jakarta (ID): Salemba Empat. 
Fandeli C dan Muhammad. 2009. Prinsip-Prinsip Dasar Mengkonservasi Lanskap. Yogyakarta (ID): UGM Pr.

Menurut Undang-Undang No. 10 Tahun 2009 tentang Kepariwisataan (pasal 1)

Maharani R. 2009. Studi Potensi LanskapPerdesaan untuk Pegembangan Agrowisata Berbasis Masyarakat di Kecamatan Cigombong Kabupaten Bogor [skripsi]. Bogor (ID): Institut Pertanian Bogor.

Mandiangan MM. 2013. Kawasan Agrowisata Di Rurukan (Arsitektur Organik). Jurnal Arsitektur DASENG Edisi Khusus TA. 2(1):9-18.

Nurisjah S. 2001. Pengembangan kawasan wisata agro (Agrotourism). Buletin Tanaman dan Lanskap 23.-indonesia. 4(2): 20

Rangkuti F. 1997. Analisis SWOT Teknik Membedah Kasus Bisnis. Jakarta (ID): PT Gramedia Pustaka Utama.

Smith (1989) dalam Maharani (2009) yang disesuaikan dan dimodifikasi dengan tujuan penelitian ini, seperti objek wisata pertanian, objek wisata alami, hingga fasilitas pendukung kegiatan agrowisata.

Suwantoro G. 2004. Dasar-dasar Pariwisata. Yogyakarta (ID): ANDI.

Budiarti T, Suwarto, Muflikhati I. 2013. Pengembangan Agrowisata Berbasis Masyarakat pada Usahatani Terpadu guna Meningkatkan Kesejahteraan Petani dan Keberlanjutan Sistem Pertanian. Jurnal Ilmu Pertanian Indonesia. Vol 18 No.3. hal 200207 